\title{
MECHANISM OF COMPLEX MINE PRESSURE MANIFESTATION ON COAL MINING WORK FACES AND ANALYSIS ON THE INSTABILITY CONDITION OF ROOF BLOCKS
}

\author{
Jingxuan X. YANG ${ }^{1)}$, Changyou Y. LIU ${ }^{1) *}$ and Bin YU ${ }^{2)}$ \\ ${ }^{1)}$ School of Mines, State Key Laboratory of Coal Resources and Safe Mining, Key Laboratory of Deep Coal Resource Ming, \\ Ministry of Education, China University of Mining \& Technology, Xuzhou, Jiangsu 221116, China \\ ${ }^{2)}$ Datong Coal Mine Group Company, Datong, Shanxi 037003, China \\ *Corresponding author's e-mail: cyliucumt@163.com
}

\section{ARTICLE INFO \\ Article history}

Received 14 October 2014

Accepted 22 January 2015

Available online 30 January 2015

\section{Keywords:}

Complex mine pressure

Instability blocks

Irregular weighting mechanism

Roof instability coefficient

Block instability condition

Block instability parameter

\section{ABSTRACT}

Irregular weighing of work faces affects normal mining of the coal seam. With respect to the features of complex mine pressure manifestation on work faces, modeling analysis was conducted on the motion instability of fractured blocks of overlying strata based on existing research. Method of probability analysis was employed to reveal the mechanism of complex mine pressure manifestation and obtain the instability conditions of fractured roof blocks. The research indicates that the rule of movement instability of fractured roof blocks obeys an exponential failure probability density function; in the context of probability description of roof block instability, the instability condition of fractured blocks is a nonhomogeneous partial differential equation; when an integer multiple of the fracture block size is used as the instability parameter of roof, the instability condition of roof depends on block size, number of fractured blocks and roof instability coefficient, and this instability parameter was utilized to explain the mechanism of irregular weighting of work faces; the weighting distance of work faces was analyzed and predicted with considerations of actual conditions of coal seam; the number of fractured blocks and the structural features of roof under the disturbance of mining on work faces were obtained by inverting the measured mine pressure data, which provides a new method to predict and forecast the manifestation of mine pressure on work faces under complex conditions of weighting.

\section{INTRODUCTION}

Currently, working resistance in-situ monitors for hydraulic supports in coal mining work faces have been widely equipped by most mines in China and received positive evaluations. The analysis of monitored data is mainly conducted by employing the method to deal with support working resistance and time-weighted resistance in traditional mine pressure theory. Results of analysis can provide a certain extent of guidance for prediction and forecast of mine pressure manifestation of work face roofs (Geng, 2002; Kidybinski, 1979). However, as the mining intensity of coal seams is increasing, mine pressure manifestation of work faces under complex coal seam mining conditions tends to be more abnormal, large/small weighting of roof become frequent and monitored data of support working resistance obviously demonstrate irregular distributions, which makes it difficult to analyze by the traditional mine pressure data processing method (Vakili et al., 2007). In the conditions of excavation of Jurassic and carbonic coal strata in Datong minefields in China, the excavation of upper Jurassic coal strata is almost completed and production is focus gradually on the lower carbonic coal strata, where coal strata No. 3 to No. 5 are the primary excavated coal strata with an average thickness of $15.72 \mathrm{~m}$. The excavation of carbonic coal strata is not only affected by the hard roofing of itself but also the roofing of Jurassic coal strata as well as the coal pillars in the gobs (Yu et al., 2014). As a result, the mining pressure during the excavation of carbonic extra-thick coal strata appears to be irregular.

With respect to the pattern of roofing activity after excavation, Heasley et al. (2001) analysed the fracturing characteristics of roofing from the perspective of microseism while Peng (1973; 1993) revealed the pattern of roofing activity and structural characteristics of roofing at the working face from the perspective of indoor rock mechanics and physical equivalent simulation. However, the condition of excavation in overseas is usually rather simply and room and pillar mining is commonly used in most minefields. As such, the space of working face after excavation is relatively small, the magnitude of activity of over-overlaid roofing is relatively low and the magnitude of appearance of mining pressure is less significant (Peng, 2013). However, due to the increase of excavating depth and thickness of long wall coal strata, the spacing of working face after excavation is large. Affected by the layered fractured block structure of the rock-overlaid roofing at large gobs and multi-gob, the dynamic load sustained by layers of each roofing is not coordinated. The layered fractured blocks are in the state of dynamic adjustment. If the working face in the condition of 
multi-gob hard roofing is analysed by the pattern of fracturing and loss of stability of a single layer of roofing, the complex movement of roofing structure and the characteristics of pressure appearance at the working face can be hardly described. Thus, large/small weighting and irregular weighting of overlying strata roofs on coal mining work faces have been under investigations of several scholars, among which C.Y. Liu and S.H. Yan proposed respectively the combined cantilever structure of immediate roof based on extra-thick coal seam mining conditions. Both of them agreed that small weighting on work faces results from periodic fracture of the combined cantilever roof and large weighting is caused by fracture instability of upper key layers. They consented on the mechanism of small weighting but provided different explanations on large weighting. Liu et al. took into account the existence of soft interlayers between close key layers and attributed strong manifestation of mine pressure on work faces to the fracture instability of upper combined key layer roofs (Liu et al., 2014). Yan et al. considered no more than the influence of fracture instability of a single key layer roof (Yu et al., 2012; Yan and Yi, 2008). In a word, these theories were proposed based on extrathick coal seam conditions and may not be suitable for explaining complex mine pressure manifestation under general coal mining conditions. To deal with this, Liu et al. proposed to employ the method of probability analysis to analyze quantitatively the features of irregular weighting in mines. For instance, features of support resistance distribution under different roof fracture manners were obtained by means of analysis incorporating Weibull's threeparameter probability function (Liu et al., 2014). However, the generalization of this method is restrained due to difficulties of determining coal seam parameters and structural parameters. With consideration of features of large/small weighting of work face roofs, C.Y. Liu employed directly the approximate analysis method with an exponential function to yield a reasonable explanation of mechanism of large/small weighting on work faces, based on which a new method to predict and forecast mine pressure on work faces under complex weighting conditions was proposed (Liu and Yang, 2014). Though this method works, the reason why the exponential function could lead to excellent effect of analysis has not been investigated deeply.

As the global movement of the hard roofing group structure and the load-carrying capacity possess certain statistical characteristics, it is possible to analyse the movement of roofing group structure and its impact on the pressure appearance at the working face from the perspective of statistical analysis. In the work reported by this paper, we provided the instability probability function of roof blocks in exponential form through strict mathematical derivations starting from the assumption of instability probability of fractured roof blocks (Lin et al., 1987;

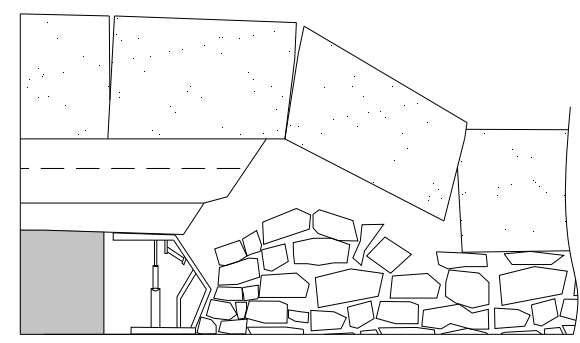

(a) roof structure under thin and moderate thick coal seam conditions

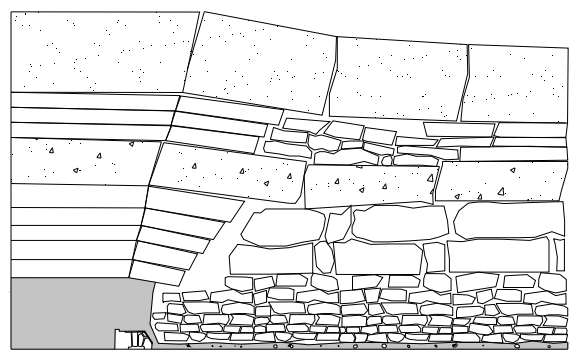

(b) roof structure under thick and extra thick coal seam conditions

Fig. 1 Roof structure under coal seam conditions with different thicknesses.

Wang et al., 2011; Shen et al., 2011; Zhu, 2006), based on which instability conditions of fracture blocks were established and mechanism of complex mine pressure manifestation on work faces were revealed.

\section{THEORETICAL ANALYSIS}

In current mine pressure theory, roof structures at different coal mining heights are considered to be different such that the greater the coal mining height is, the higher the layer at which roof fractured occurs is (Wu et al., 2014). For example, under the conditions of fully-mechanized mining of thin and moderate thick coal seams or mining with large heights, roof fracture height is finite and the periodic fracture of immediate roof of coal seam induces small-period weighting of work faces, while the fracture instability of overlying strata key layers leads to strong mine pressure manifestation on work faces, as shown in Figure 1a. Under the conditions of thick and extra thick coal seam mining, the mined out area is large, affected overlying strata layer is relatively high, the key layer roof moved upwards and multiple close roof layers in coal seam easily form a combined cantilever structure. The periodic fracture of this combined cantilever structure causes the small-period weighting on work faces. In the meantime, fracture instability of the overlying strata key layer or combined cantilever key layer leads to mine pressure manifestation of work faces (Liu et al., 2014; Yu et al., 2012), as shown in Figure 1b. 
It shows that the main source of work face support resistance is fracture instability of different roofs in the overlying strata and intensity of mine pressure manifestation with different coal seam thicknesses demonstrates different manners of distribution. However, current treatments of mine pressure data on work faces are still limited to investigations of maximum support work resistance and time-weighted resistance and research on frequently observed intermediate weighting intensity between initial support force and maximum work resistance is seldom reported. Especially for mining conditions with thick and extra thick coal seams, disturbance height of work face roofs is relatively large due to large mine out area. As mining of coal seam advances, irregular motion of roofs at different layers results in complex mine pressure manifestation on work faces and the intermediate support resistance corresponds to the motion intensity of one of the roofs.

To investigate the features of complex mine pressure manifestation on work faces, from the point of view of probability and statistics, we can assume that the instability of fractured blocks of overlying strata depends on some parameter $X$ and the instability probability of fractured blocks is $P(X)$. Thus, if the instable state of motion of fractured roof blocks is represented by parameter $X+\Delta X$, the corresponding instability probability is $P(X+\Delta X)$.

Owing to mining of coal seam and space in mined out area, fractured roof blocks undergo irregular motions and the size of work face disturbing range demonstrates a certain extent of randomness due to effects of complex mining environment and technology. Thus, motion instabilities of fractured overlying strata blocks are treated as independent events. As a result, the instability probability of an arbitrary fractured roof block within the work face disturbing range can be expresses as:

$$
P(X+\Delta X)=P(X)+P(\Delta X)[1-P(X)]
$$

where $X$ is the parameter corresponding to motion instability of fractured roof block; $\Delta X$ is the increment of the instability parameter.

Organize terms in equation (1) and take limit, which yields:

$\frac{d P}{d X}=[1-P(X)] \lim _{\Delta X \rightarrow 0} \frac{P(\Delta X)}{\Delta X}$

where,

$$
\frac{d P}{d X}=\lim _{\Delta X \rightarrow 0} \frac{P(X+\Delta X)-P(X)}{\Delta X}
$$

Equation (2) is valid for any $X$ and the value of $d P / d X$ is finite. Therefore, the function $P(\Delta X) \rightarrow 0$ as $\Delta X \rightarrow 0$, i.e. $P(0)=0$.

Without loss of generality, let:

$\lim _{\Delta X \rightarrow 0} \frac{P(\Delta X)}{\Delta X}=\frac{" 0 "}{" 0 "}=C$

where $C$ is constant.
Plugging it into equation (2), we obtain:

$\frac{d P(X)}{d X}=C[1-P(X)]$

Integration of equation (3) yields the instability probability of roof blocks:

$P(X)=1-A \exp (-C X)$

where $A$ is a constant produced by integral.

Since $P(0)=0$, we can get $A=1$ by substituting it into equation (4). Thus the instability probability of roof blocks is:

$P(X)=1-\exp (-C X)$

Equation (5) demonstrates that as the mining work face advances, fractured roof blocks undergo motion instabilities according to the distribution in form of an exponential function. By the definition of exponential distribution of failure probability, the physical meaning of constant $C$ is the instability rate of fractured roof blocks.

As generally known, the exponential distribution function of failure probability is the most fundamental and the most widely used distribution function in system reliability theory, which not only can offer good descriptions of occasional failure events but also is being widely applied in the area of complex system reliability analysis (Liu, 2002). Thereafter, employment of exponential distribution function (5) to analyze irregular roof motions under complex mining environment is feasible and reasonable.

Due to the influence of mining on working faces and space in mined out area, motion instability of roof blocks is irreversible. Assume at the moment $t$, there are $n$ fractured blocks within work face disturbing range, in which $n_{i}$ blocks undergo motion instability and $n-n_{i}$ blocks are still in equilibrium. By definition of instability probability of fractured roof blocks, in time increment $\Delta t$, the incremental number of fractured roof blocks is:

$\Delta n_{i}=\left(n-n_{i}\right) \frac{P(X)}{t_{l}} \Delta t$

where $\Delta n_{i}$ is the incremental amount of instable roof blocks; $t_{l}$ is the time in which the work face advances by a block size, $t_{l}=l / v$, where $v$ is the mean advancing speed of coal seam.

Organizing equation (6) into:

$\frac{\Delta\left(n_{i} / n\right)}{\Delta t}=\left(1-\frac{n_{i}}{n}\right) \frac{P(X)}{t_{l}}$

Since the greater the size of fractured overlying strata blocks is, the more difficult it is to maintain equilibrium among roof blocks and the more probable the coal seam roof tends to be instable (Qian and Liu, 2007; Qian and Miao, 1995; Gong and Jin, 2004), a linearly proportional relation between the instability 
rate of fractured roof blocks and the size of a single block is assumed:

$$
n_{i} / n=C=k l
$$

where $k$ is the instability coefficient of roof blocks and $l$ is the mean size of fractured blocks.

In practical mining process, the time increment of motion instability of fractured roof blocks cannot be infinitesimal and should satisfy $\Delta t \geq t_{l}$. However, for mathematical convenience, relevant functions are treated as continuous functions (discontinuous instability state of fractured roof blocks is a special form of corresponding continuous state function). Substitution of equation (8) into equation (7) yields:

$$
\frac{d(k l)}{d t}=(1-k l) \frac{P(X)}{t_{l}}
$$

When the instability coefficient of fractured roof blocks is constant, simplification and organization of equation (9) lead to a nonhomogeneous partial differential equation that the motion instability of fractured roof blocks satisfies:

$$
\frac{d l}{d t}+\frac{P(X)}{t_{l}} l=\frac{P(X)}{k t_{l}}
$$

Different cantilever lengths of the work face roof correspond to different intensities of mine pressure manifestation (Liu et al., 2014; Qian and Liu, 2007). The instability parameter of fractured roof blocks is taken as an integer multiple of the mean size of single blocks, i.e. $X=N l$. After plugging it into equation (5) and combining with equation (10), we can obtain by separation of variables:

$$
f(l) d l=\frac{v d t}{k}
$$

where,

$$
f(l)=\frac{l}{\left[1-\exp \left(-k N l^{2}\right)\right](1-k l)}
$$

where $N$ is the number of fractured roof blocks within the mining disturbing range when weighting occurs.

According to the value of instability parameter of fractured overlying strata roof blocks, the coal seam mining duration corresponding to a weighting period $t=N t_{l}$. Thus, solve equation (11) by integration in a weighting period incorporating $l / v=t_{l}$, which yields:

$\int_{0}^{N l} f(l) d l=\frac{v}{k} \int_{0}^{N t_{l}} d t=\frac{N l}{k}$

Solve equation (12) by differentiation of both sides and finally obtain the instability condition of fractured roof blocks:

$k f(N l)=1$

Expand equation (13) as:

$\exp \left(-k N^{3} l^{2}\right)=\frac{1-2 k N l}{1-k N l}$
Equation (14) indicates that the stability of fractured roof blocks depends not only on block size but also on the number instability coefficient of blocks within the mining disturbing range.

In the work reported by (Liu and Yang, 2014), the instability coefficient of fractured roof blocks was obtained by combining current mine pressure theory:

$k=\frac{\sqrt{3 \lambda K \eta}(\sqrt{3 \lambda K \eta}+1) \sin \alpha}{(3 \lambda K \eta-1) h}$

where $\lambda$ is the ratio of crushing strength and compressive strength of coal; $K$ is the boundary support coefficient of roof blocks in the range 1/2 1/3 (Qian and Liu, 2007); $\eta$ is the ratio of compressive strength and tensile strength of coal; $\alpha$ is the angle of rotation of blocks; $h$ is the thickness of roof.

Equation (15) indicates that the instability coefficient of fractured roof blocks depends mainly on occurrence characteristics of coal and boundary support conditions of blocks. Thus, for a certain mine, the instability coefficient of roof blocks is readily obtained by calculation and analysis, which can be plugged into equation (14) to acquire the influence of the number of fractured roof blocks and block size to the motion instability of roof.

The above analysis shows that the adaption of the proposed method on the analysis of complex issue of mining pressure appearance at coal strata in multigob condition avoids the specific evaluation of the dynamic characteristics of complex multi-layer roofing in multi-gob. Macroscopic mechanism of mining pressure appearance at the stope of working face is analysed, the analysis and determination of a number of parameters in complex roofing movement system are simplified and the stable conditions of multi-gob multi-layer roofing system are provided in the simplest form for ease of onsite application.

\section{APPLICATION OF ANALYSIS}

The coalfield in Jurassic Datong Formation, Datong Mining Area of China has an area of $772 \mathrm{~km}^{2}$. The thickness of strata containing coal varies within $75 \sim 264 \mathrm{~m}$ and is $201 \mathrm{~m}$ on average. 15 layers of coal seams are minable. Coal seams are complex in structure with undeveloped cracks. Unidirectional compressive strength is high, Protodyakonov coefficient $f>3$. Coal seams are composed by interbeds of powder sandstone, fine sandstone and moderate coarse sandstone, except that the layers above No. 2 coal seam are comprised of Yungang group conglomerate and glutenite. Joint fissures do not develop and have strong continuity and complete structures. The compressive strength is between 55.2 and $65.63 \mathrm{MPa}$. Currently, upper coal seams have been basically mined out and the mining of lower coal seams is significantly influenced by upper coal seams that have been mined (Yu et al., 2014).

Figure 2 shows the histogram of occurrence of coal seams No. 11 15 in Datong Mining Area. 


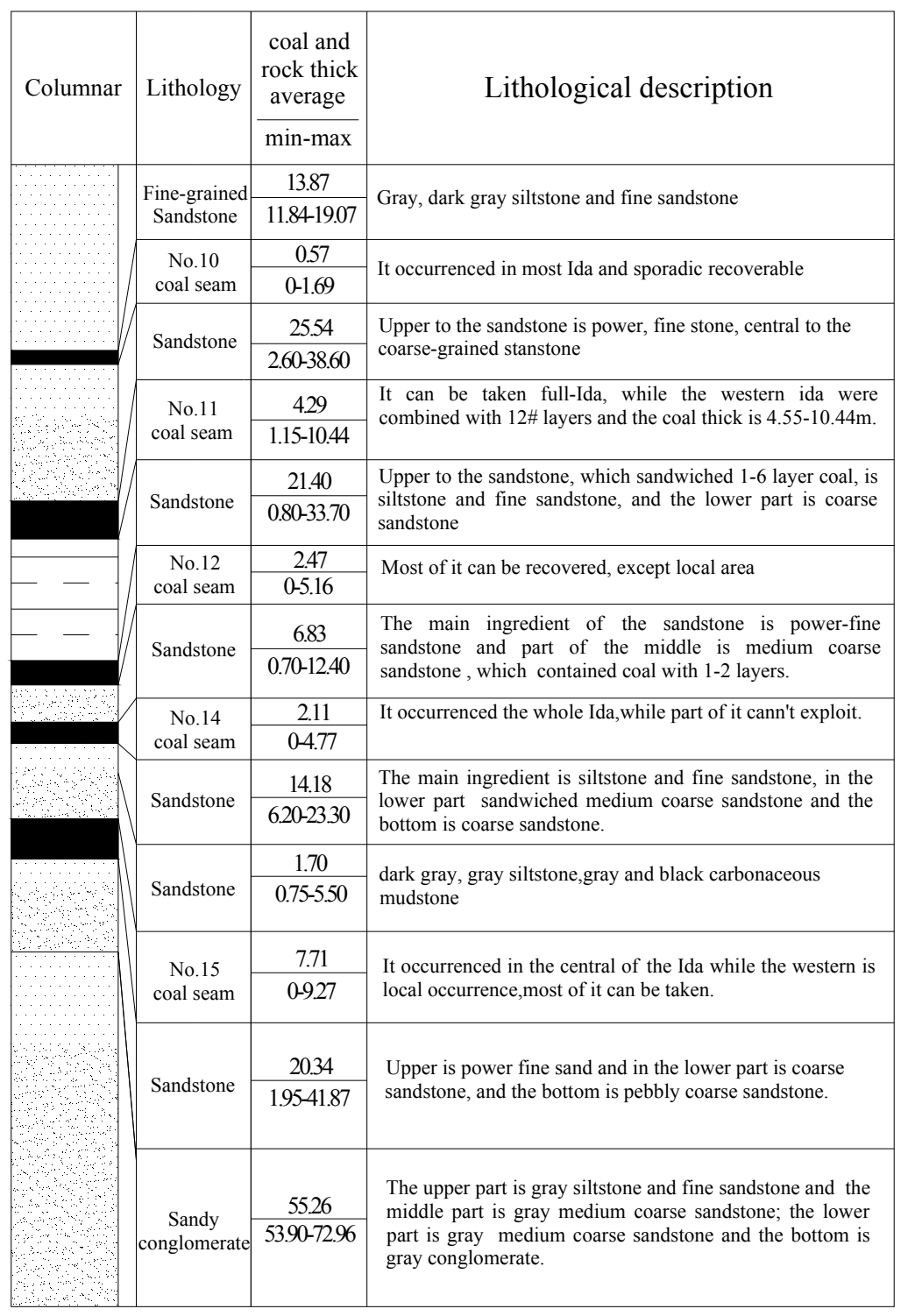

Fig. 2 Histogram of coal seam occurrence.

The coal seam No.15 is considered to be the case for analysis. Thickness of coal seam occurrence is $2.2 \sim 4.6 \mathrm{~m}$, and then angle of inclination is $1 \sim 2^{\circ}$. The structure of the coal seam has frequent bifurcations and merges. Coal seams No. 12, No. 13 and No. 14 above coal seam No. 15 had been fully mined between $1850 \mathrm{~s}$ to $1870 \mathrm{~s}$. Through real time monitoring of work face support resistance using a dynamic monitor for coal mine roofs (as shown in Fig. 3), measured data of periodic weighting distances were recorded and organized as shown in Table 1.

Through measurement of physical and mechanical properties of sandstone roof, we knew the ratio of compressive strength and tensile strength of roof was about 10 . Under the condition that both the ratio of crushing strength and compressive strength and the block boundary support coefficient were set to be 0.4 (Yang et al., 2014; Huang et al., 2000), the relation between the instability coefficient of fractured roof blocks, angle of rotation of blocks and roof thickness

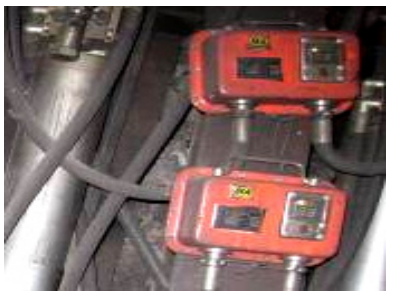

Fig. 3 Roof dynamic monitor.

Table 1 Monitored periodic weighting distances.

\begin{tabular}{ccccccc}
\hline $\begin{array}{c}\text { No. of } \\
\text { cycles }\end{array}$ & 25 & 35 & 45 & 65 & 75 & Average \\
\hline $\begin{array}{l}\text { Weighting } \\
\text { distances } / \mathrm{m}\end{array}$ & 18.3 & 17.1 & 16.5 & 16.4 & 17.4 & 17.1 \\
\hline
\end{tabular}




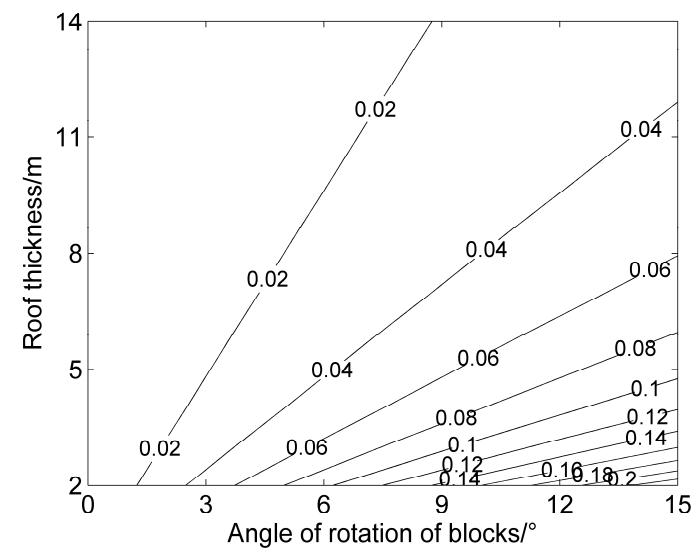

Fig. 4 Curve of instability coefficient of roof blocks.

was obtained according to equation (15), as shown in Figure 4.

Figure 4 indicates that with certain physical and mechanical properties of coal, the instability coefficient of roof blocks depends mainly on the angle of rotation of blocks and roof thickness. With a fixed roof thickness, the instability coefficient increases as the angle of rotation of blocks increases with diminishing returns. With a fixed angle of rotation of blocks, the instability coefficient decreases as the angle of rotation of blocks increases with diminishing returns.

With the specific occurrence of coal in this mine, since the instability coefficient of roof blocks was known, the curve of instability condition of fractured roof blocks was obtained by equation (13) or (14), as shown in Figure 5.

It has been known that larger size of fractured roof blocks lead to stronger mine pressure manifestation on work faces (Yu et al., 2014). The curve of instability condition of fractured roof blocks shown in Figure 5 demonstrates that:

1. With a fixed instability coefficient, the greater the number of fractured roof blocks within the mining disturbing range is, the smaller the block size is. This indicates that when overlying strata is soft or roof is fractured, size of blocks within the mining disturbing range is relatively small, but the number of fractured blocks is relatively large. Inversely, when roof is hard and it is difficult to fracture, size of blocks is relatively large but the number of fractured blocks within the mining disturbing range is relatively small.

2. With a fixed instability coefficient of roof blocks, the size of blocks corresponding to a certain number of fractured roof blocks is not unique. This means that even with a fixed number of fractured roof blocks, work face may possibly demonstrate multiple weighting intensities. Similarly, one size of roof blocks may correspond to multiple numbers of roof blocks. This elaborates the mechanism of complex weighting on work faces from the point of view of probability analysis.

3. With a fixed size of fractured roof blocks, smaller instability coefficient corresponds to greater number of fractured roof blocks within the mining disturbing range. Similarly, with a fixed number of fractured roof blocks within the mining disturbing range, the size of fractured roof blocks increases as the instability coefficient of blocks decreases. Thus, the smaller the instability coefficient of roof blocks is, the more unstable the overlying strata roof structure of work face is, and the easier it is for instability to occur among fractured roof blocks.

As a summary of above, probability analysis was employed to reveal the mechanism of complex mine pressure manifestation on work faces and the stability condition of fractured roof blocks was obtained. In addition to predict and forecast features of mine pressure manifestation on work faces, this theoretical investigation provides a basis for the inverse analysis of roof structure of work faces, which is detailed as:

1. As narrated previously, at first the instability coefficient of roof blocks was pre-determined by combining the occurrence condition and properties of coal in the specific mine. Then according to the instability condition of fractured

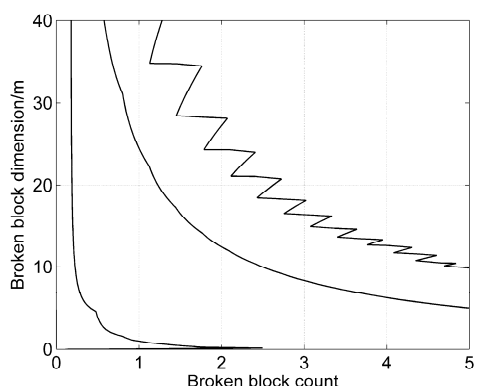

(a) $k=0.02$

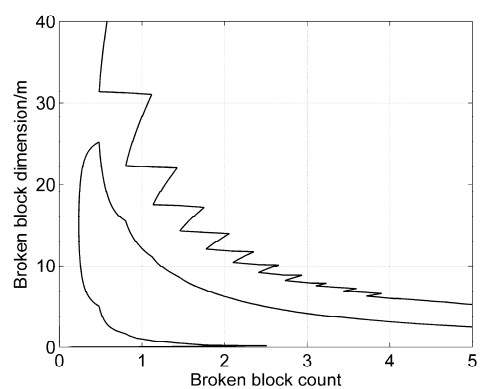

(b) $k=0.04$

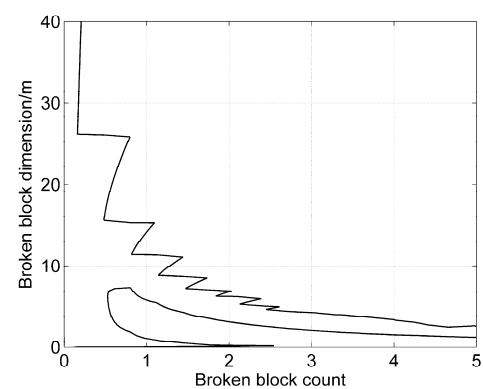

(c) $k=0.08$

Fig. 5 Curve of instability condition of fractured roof. 


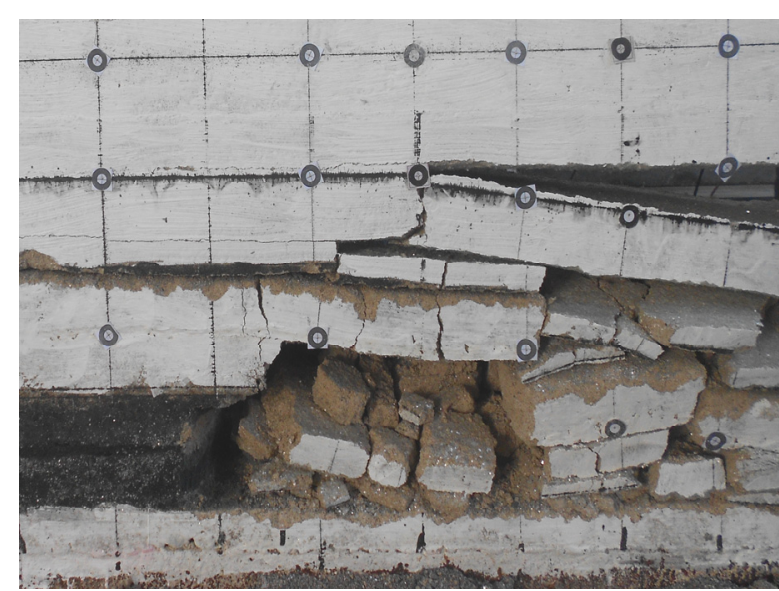

Fig. 6 Similarity modeling results of coal mining.

blocks, the relation between the number of fractured roof blocks within the mining disturbing range and the block size was determined. Later, possible weighting intensity on the work face was predicted and forecasted based on size of fractured blocks, which provides protection and foundation for safe mining on work faces and proper selection of support structure. Under the mining conditions of coal seam No. 15 in Datong Mining Area, thickness of the basic roof of overlying strata is around $14 \mathrm{~m}$ and the analyzed instability coefficient of roof blocks was between 0.02 and 0.03 . Since the disturbing space in coal mining is quite limited and similarity experiments of coal mining indicated that the number of blocks within the mining disturbing range was usually 1 3 (Qian and Miao, 1995; Gong and Jin, 2004) (as shown in Figure 6), the size of fractured roof blocks was determined according to the curve of instability of fractured roof blocks shown in Figure 5 to be between 13 and $28 \mathrm{~m}$, which matches the measured data of weighting distances.

2. Analysis results of monitored mine pressure data were used to invert the size, number and structural features of fractured roof blocks within the mining disturbing range. Under the mining conditions of coal seam No. 15, characteristics of observed roof weighting are shown in Figure 7.

It is indicated by Figure 7 that as coal mining advances, one period of mine pressure manifestation on work faces occured every 15 29 cycles of support and the corresponding periodic advancing step of the work face was about $12.0 \sim 23.2 \mathrm{~m}$ when the instability coefficient of roof blocks was considered to be $0.02 \sim 0.03$. Therefore, according to the curve of instability condition of blocks under such conditions, the number of fractured roof blocks was determined to be 2. The structural characteristics of fractured roof blocks are shown in Figure 1a.

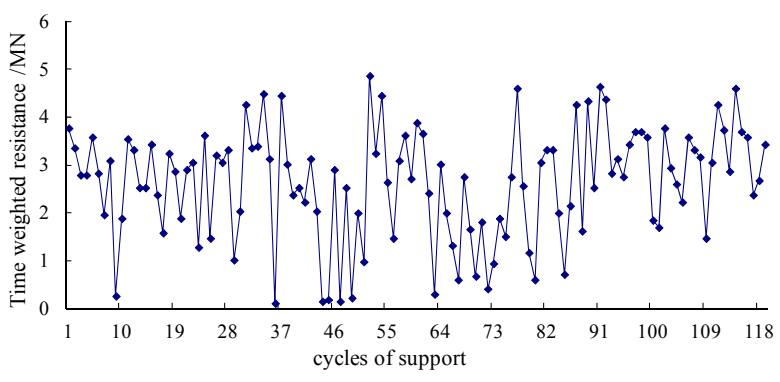

(a) The time weighting resistance of No. 37 support

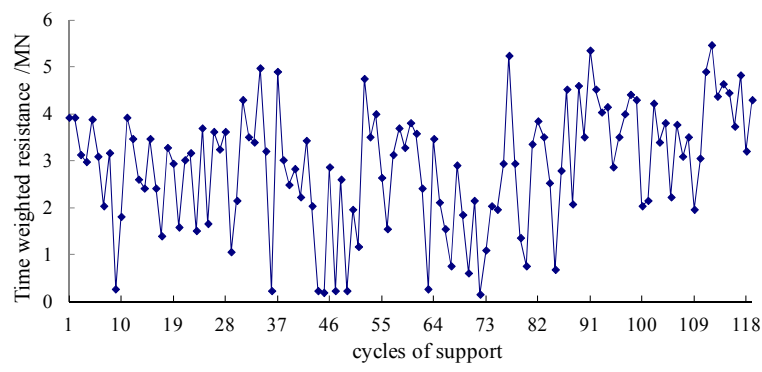

(b) The time weighting resistance of No. 85 support

Fig. 7 Characteristics of support time weighting resistance.

The use of Weibull three-parameter function on the description of complex mining pressure by former researchers achieved certain results and guided onsite application (Liu et al., 2014). However, a large number of unknown parameters are involved and undetermined in such approach and the determination of some parameters requires estimation of mining production in similar conditions. Therefore, the adaption of such approach is lack of certain pertinence. The pattern of roofing activity and structural state acquired by the conditions off exponential loss of stability of roofing matches the practical observation during production of coal mine. The number of parameters to be determined is lesser and the determination of parameters is completed directly from the occurrence of roofing which significantly simplifies the onsite application of such approach.

\section{CONCLUSIONS}

It is proved by research that the exponential failure probability function is suitable for analysis of motion instability of fractured roof blocks. The analysis conducted revealed the mechanism of complex mine pressure manifestation on work faces and obtained instability condition of roof blocks.

Results of probability analysis on instability of roof blocks demonstrate that the instability condition of fractured blocks is a nonhomogeneous partial 
differential equation, which depends on block size, number of blocks and instability coefficient of roof if an integer multiple of block size is chosen as the instability parameter.

With respect to the mining conditions of coal seam No. 15 in Datong Mining Area, the weighting distance was predicted to be $13 \sim 28 \mathrm{~m}$. Based on the weighting distance $(12.0 \sim 23.2 \mathrm{~m})$ obtained by analysis of measured mine pressure data, the number of fractured roof blocks and roof structural features under the condition of work face weighting were obtained by inverse analysis, which provides a basis for prediction and forecast of mine pressure manifestation on work faces and analysis of motion instability of fractured blocks and roof structural features.

\section{ACKNOWLEDGEMENTS}

Financial support for this work was provided by the NSFC program (No. 51174192), the Fundamental Research Funds for the Central Universities (2014ZDPY21), the Innovation Project of Graduate Students Training of Jiangsu Province (No. CXLX12_0964), and the "333" Training Foundation of Jiangsu Province (No. BRA2010024).

\section{REFERENCES}

Geng, X.W.: 2002, Mine pressure measurement and control technology. Xuzhou: China Mining University Press.

Gong, P.L. and Jin, Z.M.: 2004, Study on the structure characteristics and movement laws of overlying strata with large mining height. Journal of China Coal Society, No. 29(2), 7-12. DOI: $10.3321 / \mathrm{j}$.issn:0253-9993.2004.01.002

Huang, Q.X., Shi, P.W. and Qian, M.G.: 2000, Experiment study on the coefficients of friction and inserting of main roof block corner. Rock and Soil Mechanics, No. 21(1), 60-63.

DOI: $10.3969 /$ j.issn.1000-7598.2000.01.015

Heasley, K.A., Ellenberger, J.L. and Jeran, P.W.: 2001, An analysis of rock failure around a deep longwall using microcseismic. Proceedings of the 20th International Conference on Ground Control in Mining, S.S. Peng et al., editors. West Virginia University, Morgantown, WV, 280-286.

Kidybinski, A..: 1979, Experience with hard rock penetrometer used for mine rock stability prediction. Proceedings of the 4th International Congress on Rock Mechanics, Monteux, France, 293-301.

Liu, P.: 2002, Reliability engineering fundamentals. Beijing: China Metrology Publishing House.

Liu, C.Y. and Yang, J.X.: 2014, Mechanism and predicting method of variational weighting induced by rupture instability of hard roofs. Xuzhou: 7th International Conference on Mining Science and Technology.

Liu, C.Y., Yang, J.X., Yu, B. and Wu, F.F.: 2014, The mechanized caving support resistance determination under the conditions of hard and multilayer roof in extremely thick seam. Journal of Mining \& Safety Engineering, No. 31(6), 178-185.

Liu, C.Y., Yang, J.X., Yu, B. and Yang, P.J.: 2014, Destabilization regularity of hard thick roof group under the multi gob. Journal of China Coal Society, No. 39(3), 395-403.

DOI: $10.13225 /$ j.cnki.jccs.2013.0091

Lin, D.Z., Fairhurst, C. and Starfield, A.M.: 1987, Geometrical identification of three-dimensional rock block systems using topological techniques. International Journal of Mechanics and Mining Sciences, No. 24(6), 331-338.

DOI: $10.1016 / 0148-9062(87) 92254-6$

Peng, S.S.: 1973, Time-dependent aspects of rock behavior as measured by a servo-controlled hydraulic testing machine. International Journal of Rock Mechanics and Mining Science \& Geomechanics Abstracts. No. 10, 235-246.

Peng, S.S.: 1993, Strength of laboratory-sized coal specimens vs. underground coal pillars. Mining Engineering, No. 45(2), 157-158.

Peng, S.S.:2013, Coal mine ground control, China University of Mining and Technology Press, 269-272.

Qian, M.G. and Liu, T.C.: 2007, Mine pressure and control. Beijing: Coal Industry Press.

Qian, M.G. and Miao, X.X.: 1995, Theoretical analysis on the structural form and stability of overlying strata in longwall mining. Chinese Journal of Rock Mechanics and Engineering, No. 14(2), 97-106.

Shen, Y.J., Xu, G.L. and Zhu, K.J.: 2011, Analysis and application of reliability of blocks based on systematic quantitative methodology. Rock and Soil Mechanics, No. 32(1), 224-229.

Vakili, A., Cai, Y. and Hebblewhite, B.K..: 2007, New era in longwall top coal caving geomechanics. Proceedings of the 26th International Conference on Ground Control in Mining, S.S. Peng et al., editors. West Virginia University, Morgantown, WV, JulyAugust, 202-208.

Wang, S.H., Zhang, H. and Zhang, Y.Q.: 2011, Random structural plane cutting of a rock slope spatial block model and its key blocks analysis. Journal of Northeastern University, No. 32(3), 431-434.

Wu, F.F., Yang, J.X., Yu, B. and Chen, X.H.:2014, The roof caving height determination of the thick and extra thick coal seam. Journal of China University of Mining \& Technology, No. 43(5), 765-772.

Yan, S.H. and Yin, X.W.: 2008, Discussing about the main theoretical problems of long wall with top coal caving. Journal of China Coal Society, No. 33(5), 481-484. DOI: 10.3321/j.issn:0253-9993.2008.05.001

Yang, J.X., Liu, C.Y., Yang, P.J and, Yang, Y.: 2014, Research on roadside packing technology for end zone of steep inclined coal seam face. Rock and Soil Mechanics, 35 (2), 541-550.

Yu, B., Liu, C.Y., Yang, J.X. and Liu, J.R.: 2014, Mechanism of strong pressure reveal under the influence of mining dual system of coal pillar in Datong mining area. Journal of China Coal Society, No. 39(1), 40-46. DOI: $10.13225 /$ j.cnki.jccs.2013.1482

Yu, L., Yan, S.H. and Liu, Q.M.: 2012, Determination of support working resistance of top coal caving in extra thick coal seam. Journal of China Coal Society, No. 37(5), 737-742.

Zhu, J.: 2006, Failure likelihood and reliability of key block for jointed rock mass slope. Nanjing: Hohai University. 